\title{
Characterization of a Putative Colonization Factor (PCFO166) of Enterotoxigenic Escherichia coli of Serogroup 0166
}

\author{
By MOYRA M. MCCONNELL, ${ }^{1 *}$ HENRIK CHART, ${ }^{1}$ ANNE M. FIELD, ${ }^{2}$ \\ MARTIN HIBBERD ${ }^{1}$ AND BERNARD ROWE ${ }^{1}$ \\ ${ }^{1}$ Division of Enteric Pathogens and ${ }^{2}$ Virus Reference Laboratory, \\ Central Public Health Laboratory, 61 Colindale Avenue, London NW9 5HT, UK
}

(Received 27 October 1988; revised 5 January 1989; accepted 30 January 1989)

\begin{abstract}
Enterotoxigenic Escherichia coli (ETEC) of serogroup 0166 gave mannose-resistant haemagglutination (MRHA) with bovine and human erythrocytes. The strains did not react with antisera prepared against the known colonization factors CFA/I, CFA/II, CFA/III, CFA/IV and PCFO159:H4. Strain E7476 of serotype O166:H27, which produced heat-stable enterotoxin (ST), was examined initially. It produced fimbriae about $7 \mathrm{~nm}$ in diameter. On SDS-PAGE two possible fimbrial polypeptides of molecular mass 15.5 and $17.0 \mathrm{kDa}$ were seen. When variants of strain E7476 were isolated, loss of ST and MRHA together was associated with loss of a $98 \mathrm{MDa}$ plasmid, while loss of ST alone correlated with plasmid deletion. An absorbed anti-strain E7476 antiserum reacted specifically with the 15.5 and $17.0 \mathrm{kDa}$ polypeptides in Western immunoblotting and bound to the intact fimbriae by immuno-electron microscopy. When this antiserum was used in an ELISA to examine other strains of serogroup O166, a positive reaction was obtained with all the ST- and MRHA-positive strains. One strain of serotype O71:H27 and two strains of serotype $\mathrm{O} 98: \mathrm{H}^{-}$also reacted with the absorbed anti-strain $\mathrm{E} 7476$ antiserum. The antiserum did not react with ETEC carrying known colonization factors. E. coli $\mathrm{K} 12$ and a number of $E$. coli of different serotypes carrying a plasmid coding for ST transferred from strain E7476, all gave MRHA and reacted with the absorbed anti-strain E7476 antiserum. The term putative colonization factor $\mathrm{O} 166$ (PCFO166) is proposed to describe the adhesive factor(s) on ETEC of serogroup O166 because of the similarity of properties with those of known colonization factors.
\end{abstract}

\section{INTRODUCTION}

Enterotoxigenic Escherichia coli (ETEC) are a leading cause of diarrhoea in infants in developing countries and in travellers to these countries (Sack, 1975; Merson et al., 1980). The ability of ETEC to adhere to, and colonize the small intestine is essential for pathogenicity and is due to colonization factors. These are usually fimbriae, many of which have the ability to agglutinate red blood cells from a number of animal species in the presence of mannose (Parry \& Rooke, 1985; De Graaf \& Mooi, 1986). A number of adhesins have now been identified in ETEC of human origin, viz. colonization factor antigen (CFA)/I, CFA/II, CFA/III and CFA/IV (PCF8775) and PCFO159:H4 (Evans et al., 1975; Evans \& Evans, 1978; Honda et al., 1984; Thomas et al., 1985; Tacket et al., 1987; McConnell et al., 1988). CFA/I, CFA/III and PCFO159:H4 are single fimbrial antigens while CFA/II and CFA/IV are both antigen complexes. Strains producing CFA/II possess one or other of the fimbrial antigens CS1 or CS2 and a fibrillar antigen CS3, or may possess CS3 alone (Cravioto et al., 1982; Smyth, 1982); ETEC producing CFA/IV have the fimbrial antigen CS4 or CS5 and a second antigen CS6

\footnotetext{
Abbreviations: CFA, colonization factor antigen; CS, coli surface antigen; ETEC, enterotoxigenic Escherichia coli; LT, heat-labile enterotoxin; MRHA, mannose-resistant haemagglutination; PCF, putative colonization factor; ST, heat-stable enterotoxin.
} 
(Thomas et al., 1985). ETEC producing CS5-like fimbriae or only CS6 have also been identified (McConnell et al., 1986; McConnell \& Rowe, 1989). Other possible colonization factors have also been described, viz. INT407 on ETEC of serotype O27:H7 or O27:H20 (Thomas, 1985), colonization factors on ETEC of serotype O148:H28 (Knutton et al., 1987; McConnell et al., 1988) and 2230 on a strain of serotype O25:H16 (Darfeuille-Michaud et al., 1986).

Surveys of ETEC have shown that each colonization factor is associated with particular $O$ serogroups and enterotoxin types. Some appear to be very specific. CS1 with CS3 has only been reported in strains of serotype $\mathrm{O} 6: \mathrm{H} 16$ or $\mathrm{H}^{-}$which produce heat-stable enterotoxin (ST) and heat-labile enterotoxin (LT) and one $\mathrm{ST}^{+} \mathrm{LT}^{+}$strain of serotype $\mathrm{O} 139: \mathrm{H} 28$ (Cravioto et al., 1982; Smyth, 1982; Scotland et al., 1985); CS2 with CS3 in ST ${ }^{+} \mathrm{LT}^{+}$strains of serotype O6:H16 or $\mathrm{H}^{-}$(Cravioto et al., 1982; Smyth, 1982); CFA/III with CS6 in $\mathrm{LT}^{+}$strains of serotype O25 : H16 or $\mathrm{H}^{-}$(Honda et al., 1983, 1984; McConnell et al., 1988; McConnell \& Rowe, 1989); CS4 with CS6, in ST+LT+ strains of serotype O25:H42 (Thomas et al., 1985; McConnell et al., 1985) and PCFO159:H4 in $\mathrm{ST}^{+} \mathrm{LT}^{+}$strains of serotype O159:H4 or H20 (Tacket et al., 1987; McConnell \& Rowe, 1989).

The range of $\mathrm{O}$ serogroups of strains carrying other factors is much more diverse. $\mathrm{CFA} / \mathrm{I}$ has been reported in $\mathrm{ST}^{+}$and $\mathrm{ST}^{+} \mathrm{LT}^{+}$strains of serogroups $\mathrm{O} 4, \mathrm{O} 7, \mathrm{O} 15, \mathrm{O} 20, \mathrm{O} 25, \mathrm{O} 63, \mathrm{O} 78, \mathrm{O} 90$, O104, O110, O126, O128, O136, O153 and O159 (Evans \& Evans, 1978; Cravioto et al., 1982; Thomas \& Rowe, 1982; Levine et al., 1983; Changchawalit et al., 1984; Darfeuille-Michaud et al., 1987); CS3 as a single adhesive factor in $\mathrm{ST}^{+} \mathrm{LT}^{+}$strains of serogroups O8, O78, O80, O85, O115, O128, 0139 and O168 (Evans \& Evans, 1978; Cravioto et al., 1982; Thomas \& Rowe, 1982; Levine et al., 1983; Scotland et al., 1985); CS5 together with CS6 in ST ${ }^{+}$strains of O6, O29, O92, O114, O115 and O167 (Thomas et al., 1985; McConnell et al., 1985; Manning et al., 1987; McConnell \& Rowe, 1989); CS5-like fimbriae in $\mathrm{LT}^{+} \mathrm{ST}^{+}$strains of serotype O15 and $\mathrm{LT}^{+}$ strains of serotype O114, (McConnell \& Rowe, 1989) and CS6 in ST ${ }^{+}$strains of serogroups O27, O92, O148, O153, O159 and O169 (McConnell et al., 1985, 1986). However, the same surveys also show that there are still some serogroups of ETEC where no colonization factor has been identified. These ETEC frequently produce only LT (Changchawalit et al., 1984; McConnell et al., 1985; Cravioto et al., 1988; McConnell \& Rowe, 1989). Since it has been suggested that ETEC vaccines could be prepared using adhesins, it is important to try to identify the colonization factors on these strains.

In the Division of Enteric Pathogens (DEP) there is a large collection of ETEC which have been serotyped. These strains come principally from Asia, but also included are strains from South America, Africa, the USA and Europe. Approximately 1200 strains received between 1975 and 1986 were confirmed as enterotoxigenic. Among these strains about $17 \%$ belong to 25 serogroups where no colonization factor has been identified. Of these strains approximately $30 \%$ produce ST, $60 \%$ produce LT and $10 \%$ produce ST and LT. Strains of serogroup O166 formed the largest group that produce ST only. It was decided to look for a possible colonization factor in these strains and then to examine other ETEC for this factor.

\section{METHODS}

Bacterial strains. Seventeen ST-producing and one ST-negative $E$. coli of serogroup O166, including strain E7476 (Scotland et al., 1979), were examined (Table 1). These strains were all negative for LT. Most of these strains have been described previously (Gross et al., 1985). Since enterotoxin production is coded for by plasmids which may be lost from strains on storage (Evans \& Evans, 1978), a single colony of each culture was used which was shown to be positive for ST production immediately before the start of these tests, e.g. strain E7476A (Table 1).

Ninety-nine ETEC with known colonization factors, i.e. CFA/I, CFA/II, CFA/III, CFA/IV or PCFO159:H4, and 106 ETEC with no known colonization factor, were tested. Included in the $106 \mathrm{ETEC}$ with no known colonization factor were $\mathrm{LT}^{+}$strains of serogroups $\mathrm{O} 8, \mathrm{O} 15$ and $\mathrm{O} 159$, since colonization factors had only been found in $\mathrm{ST}^{+}$or $\mathrm{ST}^{+} \mathrm{LT}^{+}$strains of these serogroups, and strains of serogroups $\mathrm{O} 7$ and $\mathrm{O} 20$, since, although $\mathrm{CFA} / \mathrm{I}$ has been reported in strains of these serogroups it has not been detected in strains of these two serogroups characterized by the DEP.

Non-enterotoxigenic nalidixic-acid-resistant strains of serotypes $\mathrm{O} 6: \mathrm{H} 16, \mathrm{O} 40: \mathrm{H} 3, \mathrm{O} 71: \mathrm{H} 48, \mathrm{O} 128: \mathrm{H} 10$, O128:H49, O154:H4 and O159:H34, into which the autotransferring ST plasmid TP224:: Tn 10 from strain 
Table 1. ETEC of serogroup 0166

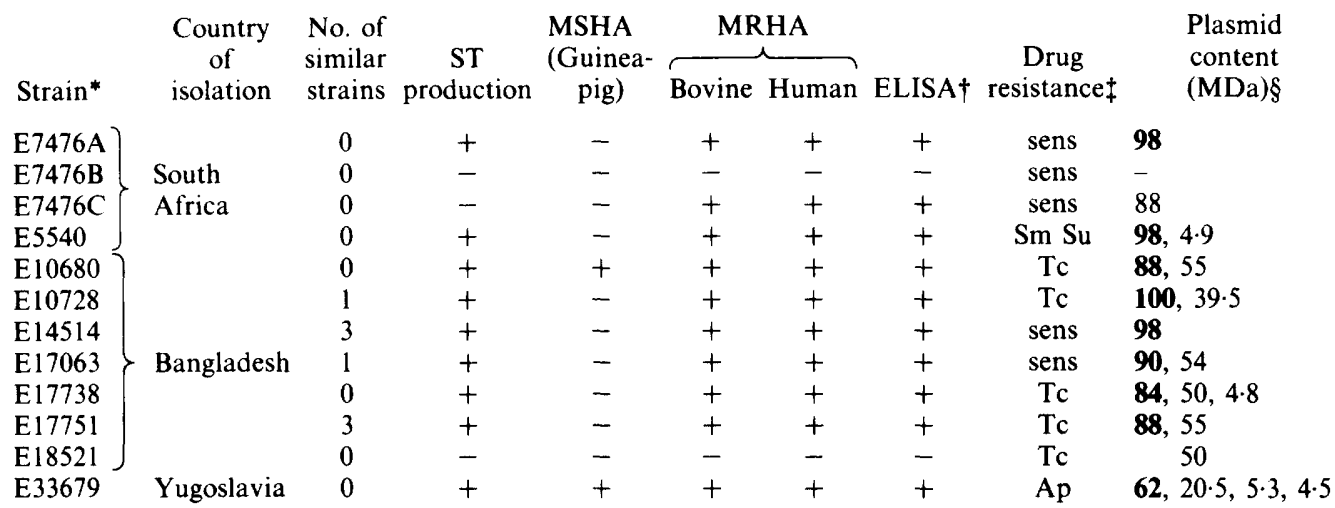

* The strains were all of flagellar type H27 except strain E33679 which was H48.

$\dagger$ ELISA against absorbed anti-strain E7476 antiserum.

‡ Symbols for drug resistance: Ap, ampicillin; Sm, streptomycin; Su, sulphonamides; Tc, tetracycline; sens, sensitive.

$\S$ Plasmids in bold type code for ST.

E7476 had been transferred (Scotland et al., 1979) were also tested. These strains have been described previously (Scotland et al., 1983).

Test for resistance to antibacterial drugs and colicin E2. Strains were tested for drug resistance by the methods of Anderson \& Threlfall (1974). Colicin resistance was detected by the agar overlay method of Frédéricq (1957).

Enterotoxin tests for $S T$ and $L T$. Two methods of testing were used for each enterotoxin. For small numbers of strains ST production was detected in the infant mouse (Dean et al., 1972) and LT production with Y1 adrenal cells in tissue culture as previously described (Donta et al., 1974). For testing a large number of single colonies, DNA probes for ST and LT were used. These comprised synthetic oligonucleotides labelled with alkaline phosphatase and supplied in kit form (SNAPR system; DuPont-NEN). The ST probe contained both STA1-and STA2-specific sequences. Hybridization to colonies was done by methods recommended by the manufacturer (McConnell et al., 1988).

Mannose-sensitive and mannose-resistant haemagglutination (MSHA and MRHA). For testing for type-1 fimbriae, strains were grown statically in nutrient broth (Difco). Samples $(1 \mathrm{ml})$ of culture were centrifuged and the cells resuspended in $0.2 \mathrm{ml}$ of nutrient broth for testing for MSHA with guinea-pig red blood cells as previously described (Cravioto et al., 1982). The strains were subcultured every $48 \mathrm{~h}$ for up to 12 times for MSHA testing.

For the first tests from solid medium the strains were grown on MacConkey agar and then overnight on CFA agar and tested for MSHA and MRHA of bovine, human and guinea-pig red blood cells as previously described (Cravioto et al., 1982). Freshly drawn Rhesus-positive group O human blood was used. For most tests the strains were grown overnight on CFA agar containing Bacto-Bile salts no. 3 (Difco) $\left(1.5 \mathrm{~g} \mathrm{l}^{-1}\right)$.

Isolation of MRHA-negative and ST-negative variants of strain E7476. Three strategies were tried: $(a)$ one hundred colonies were picked from MacConkey plates to CFA slopes and tested for MRHA. (b) Approximately 500 colonies were replicated onto filters and tested for ST genes with a DNA probe. (c) Plasmid TP224:Tn 10 was transferred into strain E7476A in an overnight cross. Tetracycline-resistant transconjugants were selected on MacConkey agar plates containing tetracycline $\left(10 \mu \mathrm{g} \mathrm{ml}^{-1}\right)$ and colicin E2 $\left(10^{3}\right.$ units ml $\left.{ }^{-1}\right)$ to counter-select against the donor. One transconjugant was grown overnight in nutrient broth, plated onto nutrient agar and then replicated onto nutrient agar plates containing tetracycline $\left(10 \mu \mathrm{g} \mathrm{ml}^{-1}\right)$. Colonies sensitive to tetracycline were examined further.

Preparation of antiserum. An antiserum was raised against strain E7476A by injecting rabbits intraperitoneally with a formalinized suspension containing about $10^{9}$ bacteria $\mathrm{ml}^{-1}$ as previously described (Thomas et al., 1985). The antiserum was absorbed with an MRHA-negative derivative, variant E7476B (Table 1).

Immunodiffusion. The antisera were tested by the Ouchterlony gel immunodiffusion technique as previously described (Cravioto et al., 1982). Antigens were prepared by suspending cultures from a $150 \mathrm{~mm}$ diameter plate containing CFA agar with bile salts $\left(1.5 \mathrm{~g} \mathrm{l}^{-1}\right)$ in $1.5 \mathrm{ml}$ saline $(0.15 \mathrm{M})$ and heating the suspensions for $30 \mathrm{~min}$ at $60^{\circ} \mathrm{C}$. The slides were examined for precipitin lines for 24 to $48 \mathrm{~h}$. In some cases the slides were washed in saline for $48 \mathrm{~h}$ followed by a wash in distilled water for a further $24 \mathrm{~h}$. Then they were dried and stained at $37^{\circ} \mathrm{C}$ for 30 min with Coomassie blue (Weeke, 1973). 
Plasmid DNA studies. Plasmid DNA was prepared by the method of Birnboim \& Doly (1979) and separated by electrophoresis on $0.6 \%(\mathrm{w} / \mathrm{v})$ agarose gels as described previously (Willshaw et al., 1979). Molecular masses of the plasmids were determined relative to plasmid standards run on the same gel.

DNA hybridization. Plasmids encoding production of ST were identified with a specific ST probe. Plasmid DNAs of wild-type strains and ST-negative variants were separated by agarose gel electrophoresis and blotted to nylon membranes (Hybond $\mathrm{N}$; Amersham). Gels were acid treated $(0 \cdot 25 \mathrm{M}-\mathrm{HCl}$ ) before denaturation of the DNA. The DNA was bound to the filter by baking $\left(80^{\circ} \mathrm{C}, 2 \mathrm{~h}\right)$. The ST probe was as described in the enterotoxin test section. Hybridization to blotted plasmid DNA was by methods recommended by the manufacturer.

Preparation of fimbriae. Crude preparations of fimbriae were prepared by suspending bacteria from $150 \mathrm{~mm}$ CFA agar plates containing bile salts in $1.5 \mathrm{ml}$ saline $(0.15 \mathrm{M})$ and heating the suspensions for $30 \mathrm{~min}$ at $60^{\circ} \mathrm{C}$. They were centrifuged in a microcentrifuge $(5000 \mathrm{~g}, 5 \mathrm{~min})$ and the supernatant fractions harvested. Following protein determinations (Lowry method) preparations were stored at $-10^{\circ} \mathrm{C}$.

$S D S-P A G E$. This was done by the method of Laernmli (1970) using vertical slab gels. Extracts were run on a $20 \%(\mathrm{w} / \mathrm{v})$ polyacrylamide gel for $3.5 \mathrm{~h}$ at $50 \mathrm{~mA}$. Proteins of known molecular mass were run on the same gel. Immunoblotting was performed as described by Stevenson \& Griffiths (1985). Protein profiles immobilized on nitrocellulose sheets were reacted with the absorbed anti-strain E7476A antiserum and antibody-antigen complexes detected using an anti-rabbit IgG antibody (Miles Scientific) radiolabelled with ${ }^{125} 1$. Each profile was reacted with approximately $5 \mu \mathrm{g} \mathrm{IgG} \mathrm{containing} 10^{6} \mathrm{c.p} . \mathrm{m}$.

Electron microscopy. The strains to be used for electron microscopy were grown on MacConkey agar then on CFA agar for $24 \mathrm{~h}$ to give maximum expression of the colonization factor(s) and to suppress the production of type-1 fimbriae. The strains were tested for type-1 fimbriae production by checking for MSHA of guinea-pig red blood cells. The bacteria were prepared for electron microscopy and immuno-electron microscopy as previously described (McConnell et al., 1981).

ELISA. Strains to be tested in the ELISA were first streaked on MacConkey agar before overnight incubation on CFA agar slopes. The cultures were checked for MRHA and suspended in $2 \mathrm{ml} 0.05 \mathrm{M}$-carbonate/bicarbonate buffer (pH 9.6) and heated at $60{ }^{\circ} \mathrm{C}$ for $30 \mathrm{~min}$. The ELISAs were done as previously described (McConnell \& Rowe, 1989). The heated suspensions were used to coat the microtitre plates. CFAs on the ETEC were identified with specific absorbed antisera or IgG. Binding of the antibody was detected using anti-rabbit IgG peroxidase conjugate. The substrate was prepared by adding $9 \mathrm{mg} o$-phenylenediamine and $40 \mu 130 \%(\mathrm{v} / \mathrm{v}) \mathrm{H}_{2} \mathrm{O}_{2}$ to $25 \mathrm{ml}$ $0.1 \mathrm{M}$-sodium phosphate buffer $(\mathrm{pH} \mathrm{6.0)} ; 100 \mu \mathrm{l}$ was added to each well and the plates were incubated in the dark at room temperature for $10 \mathrm{~min}$. Sulphuric acid $(2 \mathrm{M}, 25 \mu \mathrm{l})$ was added to each well to stop the reaction.

\section{RESULTS}

\section{Properties of strain E7476}

Strain E7476 was examined by Scotland et ai. (1979) as part of a study of enterotoxin plasmids of drug-resistant strains of $E$. coli of human origin. It was reported at that time as belonging to an unidentifiable $\mathrm{O}$ serogroup, possessing flagellar antigen $\mathrm{H} 27$, producing $\mathrm{ST}$ but not LT, being resistant to streptomycin and sulphonamides and possessing two plasmids. The $\mathrm{O}$ serogroup to which strain E7476 belongs has now been designated O166 (Gross et al., 1985). A single STpositive colony of strain E7476 (designated E7476A) was selected for examination for a colonization factor. It was no longer drug resistant and contained only one plasmid (Table 1).

When strain E7476 was originally tested after transfer from Dorset egg medium to CFA agar and overnight incubation, no MRHA of human, guinea-pig or bovine red blood cells was detected (Gross et al., 1985). However, when strain E7476A was streaked on MacConkey agar and then onto CFA agar, strong MRHA of human and bovine red blood cells occurred, while MRHA of guinea-pig red blood cells was still negative. This technique had previously been shown to improve the expression of MRHA with a strain of serotype O15: H11 (Thomas, 1985). When strain E7476A was streaked directly from a Dorset egg slope to MacConkey, Nutrient, Brain Heart Infusion or Mueller-Hinton agar no MRHA was detected. It was subsequently found that if strain E7476A was transferred directly from a Dorset egg slope to CFA agar containing bile salts, the culture gave good MRHA when mixed with bovine or human red blood cells. Strain E7476A was negative for MSHA of guinea-pig blood after growth in nutrient broth indicating the absence of type-1 fimbriae.

Strain E7476A was tested in ELISAs with antisera against the colonization factors CFA/I, CFA/II (CS1, CS2, CS3), CFA/III, CFA/IV (CS4, CS5, CS6) and PCFO159:H4. These sera were found not to react with strain $\mathrm{E} 7476 \mathrm{~A}$. 

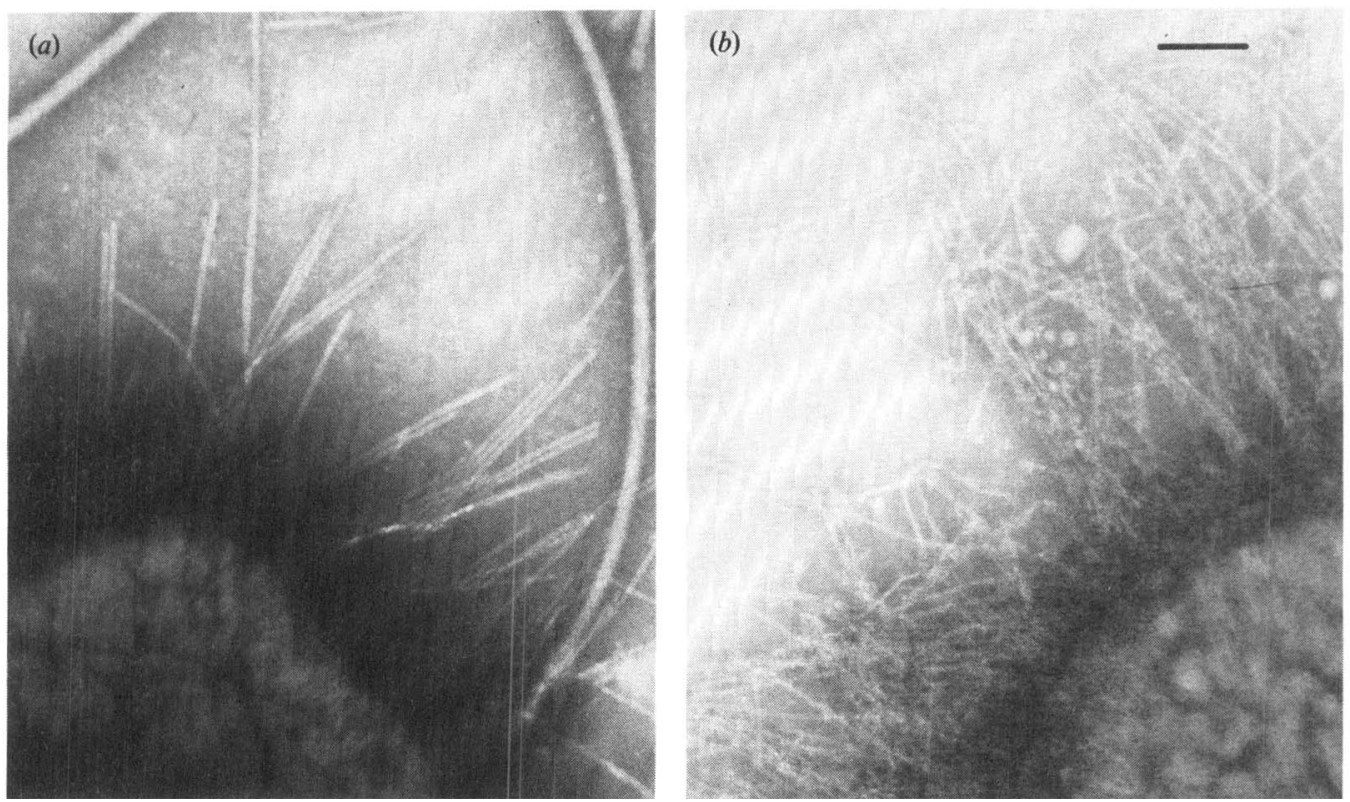

Fig. 1. Immuno-electron microscopy of fimbriate strain E7476A. (a) Strain E7476A showing fimbriae of about $7 \mathrm{~nm}$ diameter. (b) Fimbriate strain E7476A treated with absorbed antiserum raised against E7476A. Antibody molecules are attached to the fimbriae. Negative stain, $1 \%$ phosphotungstic acid (pH 6.4). Bar, $100 \mathrm{~nm}$.

\section{Isolation of MRHA- and ST-negative variants of strain E7476}

One hundred colonies, picked from a MacConkey agar plate to CFA agar slopes, were tested for MRHA with bovine red blood cells. All were MRHA positive.

Since many colonization factors are coded for by the same plasmid as codes for enterotoxin production (McConnell et al., 1981; Smith et al., 1983; Thomas et al., 1987) it was decided to look for an ST-negative variant of strain E7476 which might also be MRHA-negative. About 500 colonies were replicated onto filters and tested with the ST probe. One ST-negative colony (variant E7476C) was isolated. It was still MRHA-positive and contained an $88 \mathrm{MDa}$ plasmid (Table 1), indicating a deletion to the $98 \mathrm{MDa}$ plasmid of strain E7476A.

A third attempt to isolate a MRHA-ST-negative colony was made. Plasmid TP224:: Tn 10 was transferred into strain E7476A; the transconjugants were still MRHA positive. One transconjugant was tested for loss of tetracycline resistance. In total, 1500 colonies of this transconjugant were examined and two tetracycline-sensitive colonies were isolated. One colony (variant E7476B) was tested and found to be $\mathrm{ST}^{-} \mathrm{MRHA}^{-}$and contained no plasmid DNA (Table 1).

\section{Characterization of strain E7476A and variants E7476B and E7476C}

An antiserum was prepared to strain E7476A and absorbed twice with variant E7476B. Heated suspensions of strains E7476A, B and C were tested by immunodiffusion against absorbed anti-strain E7476A antiserum. A single immunoprecipitate was seen between the antigen and antiserum wells with suspensions of strains E7476A and C. No immunoprecipitate was observed with variant E7476B.

Before electron microscopy the strains were grown on solid media. No type-1 fimbriae were detected by MSHA of guinea-pig red blood cells. Fimbriae of about $7 \mathrm{~nm}$ diameter were produced by strain E7476A (Fig. 1 a) and variant E7476C. No fimbriae were detected on variant E7476B. The absorbed anti-strain E7476A antiserum bound to fimbriae of strain E7476A in situ (Fig. $1 b$ ) and variant E7476C (result not shown). 
(a)

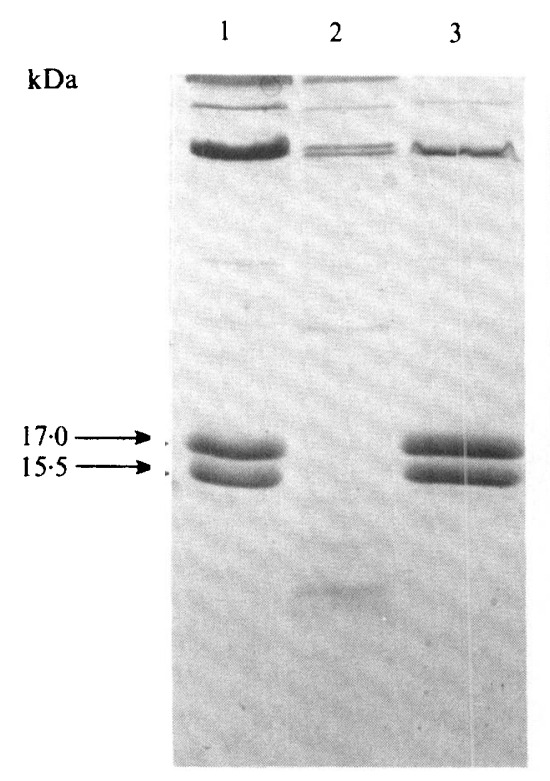

(b)

$4 \quad 5 \quad 6$

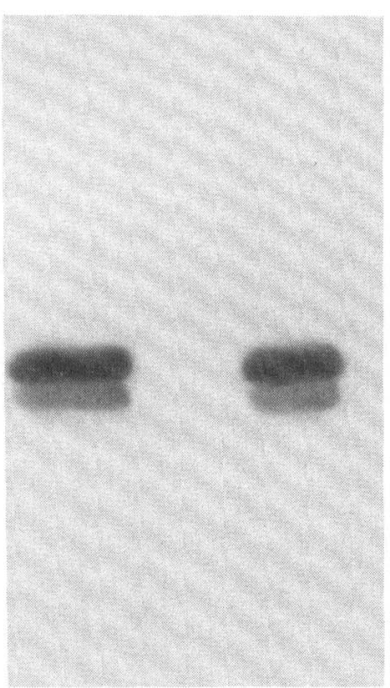

Fig. 2. SDS-PAGE profiles of fimbrial preparations from MRHA-positive and -negative variants of strain E7476. (a) Coomassie-blue-stained profiles; $(b)$ autoradiogram of a Western immunoblot showing extracts reacted with antiserum raised against strain E7476A which had been absorbed with variant E7476B. Protein profiles were reacted with $30 \mu \mathrm{l}$ antiserum followed by $5 \mu \mathrm{g}{ }^{125}$ I-labelled antirabbit antibody (106 c.p.m.). Strain E7476A (lanes 1 and 4); variant E7476B (lanes 2 and 5); variant E7476C (lanes 3 and 6). Strains E7476A and E7476C, which are both MRHA positive and fimbriate, expressed two polypeptides of 15.5 and $17.0 \mathrm{kDa}$ (lanes 1 and 3), which were absent from the MRHAnegative derivative E7476B. These two polypeptides reacted with the absorbed antiserum (lanes 4 and 6) raised against strain $\mathrm{E} 7476 \mathrm{~A}$ as above. The protein load was $30 \mu \mathrm{g}$ per lane.

When fimbrial preparations of strains E7476A and C were run on SDS-PAGE two prominent polypeptide bands of molecular masses approximately 15.5 and $17.0 \mathrm{kDa}$ were observed (Fig. $2 a$ ). No prominent bands of this size were seen on the E7476B track. These polypeptides reacted with the absorbed anti-strain E7476A antiserum (Fig. 2b).

\section{Screening of other strains of serogroup 0166}

Seventeen strains of serogroup O166 from the DEP culture collection were tested. Sixteen of the strains produced ST and were MRHA positive with bovine and human red blood cells (Table 1). Fifteen of these strains possessed the flagellar antigen $\mathrm{H} 27$ and one, strain E33679, the flagellar antigen H48. The ST-positive strains gave a positive reaction in an ELISA with antiserum raised against strain E7476A (Table 1). Five MRHA positive strains - E5540, E14514, E17063, E17738 and E17751 - were examined by electron microscopy and were seen to be fimbriate. All 17 strains were negative in ELISAs when tested with antisera raised to CFA/I, CFA/II, CFA/III, CFA/IV and PCFO159:H4.

All the ST-positive strains except strain E33679 contained a plasmid of molecular mass 84 to $100 \mathrm{MDa}$, i.e. similar in size to plasmid TP224 (Scotland et al. 1979). These plasmids all hybridized with the ST probe (Table 1). Strain E33679 had four plasmids, the largest of which (molecular mass $62 \mathrm{MDa}$ ), hybridized with the ST probe (Table 1). When heat-released extracts of MRHA-positive strains were examined by SDS-PAGE, all 16 strains were found to produce polypeptides of 15.5 and $17.0 \mathrm{kDa}$ which reacted with the absorbed anti-strain E7476A antiserum in immunoblots.

One strain of serotype O166:H27, E18521, had been sent to the DEP as ST positive but was negative on testing. Strain E18521 did not give MRHA of bovine or human red blood cells and 
Table 2. Reaction of ETEC with known and no known colonization factors with absorbed anti-strain E7476A antiserum

\begin{tabular}{|c|c|c|c|}
\hline $\begin{array}{l}\text { Colonization } \\
\text { factor }\end{array}$ & Enterotoxin & $\begin{array}{l}\text { Total no. } \\
\text { of strains }\end{array}$ & Serogroup* \\
\hline CFA/I & $\begin{array}{l}\text { ST or } \\
\text { ST and LT }\end{array}$ & 21 & $\mathrm{O} 4(3) \mathrm{O} 63(4) \mathrm{O} 78(4) \mathrm{O} 126(5) \mathrm{O} 28(3) \mathrm{O} 36(1) \mathrm{O} 153(1)$ \\
\hline CFA/II & ST and LT & 13 & $\mathrm{O} 6(4) \mathrm{O} 8(3) \mathrm{O} 85(2) \mathrm{O} 115(2) \mathrm{O} 139(2)$ \\
\hline $\mathrm{CFA} / \mathrm{III}+\mathrm{CS} 6$ & LT & 5 & $\mathrm{O} 25(5)$ \\
\hline CFA/IV & $\begin{array}{l}\text { ST or LT or } \\
\text { ST and LT }\end{array}$ & 56 & $\begin{array}{c}\mathrm{O} 15(3) \mathrm{O} 25(4) \mathrm{O} 27(5) \mathrm{O} 29(1) \mathrm{O} 79(1) \mathrm{O} 85(1) \mathrm{O} 114(22) \\
\mathrm{O} 115(3) \mathrm{O} 148(4) \mathrm{O} 153(2) \mathrm{O} 159(4) \mathrm{O} 167(4) \mathrm{O} 169(2)\end{array}$ \\
\hline PCFO159:H4 & ST and LT & 4 & $0159(4)$ \\
\hline None of above & ST & 14 & $\begin{array}{l}\mathrm{O} 2(1) \mathrm{O} 9(1) \mathrm{O} 20(3) \mathrm{O} 30(1) \mathrm{O} 34(3) \mathrm{O} 49(1) \mathrm{O} 64(2) \\
\text { O71(1)† O76(1) }\end{array}$ \\
\hline None of above & LT & 76 & $\begin{array}{l}\mathrm{O} 7(11) \mathrm{O} 8(2) \mathrm{O} 9(1) \mathrm{O} 15(2) \mathrm{O} 17(6) \mathrm{O} 20(1) \mathrm{O} 21(2) \\
\mathrm{O} 40(1) \mathrm{O} 41(1) \mathrm{O} 48(1) \mathrm{O} 59(1) \mathrm{O} 64(3) \mathrm{O} 79(1) \mathrm{O} 80(1) \\
\mathrm{O} 88(8) \mathrm{O} 101(2) \mathrm{O} 104(1) \mathrm{O} 112(2) \mathrm{O} 114(10) \mathrm{O} 117(5) \\
\mathrm{O} 146(2) \mathrm{O} 159(12)\end{array}$ \\
\hline \multirow[t]{2}{*}{ None of above } & ST and LT & 16 & $\begin{array}{l}\mathrm{O} 1(1) \mathrm{O} 7(1) \mathrm{O} 17(1) \mathrm{O} 20(6) \mathrm{O} 60(1) \mathrm{O} 98(2) \dagger \\
\mathrm{O} 109(3) \mathrm{O} 159(1)\end{array}$ \\
\hline & & 205 & \\
\hline
\end{tabular}

* The numbers of strains of each serogroup tested are given in brackets.

$\dagger$ These strains reacted with absorbed anti-strain E7476A antiserum

gave a negative reaction in the ELISA with the absorbed anti-strain E7476A antiserum. It appeared to have lost the plasmid which codes for ST and MRHA (Table 1).

\section{Testing of ETEC of other serotypes by ELISA}

Ninety-nine strains producing known colonization factors were tested with absorbed antistrain E7476A antiserum in an ELISA using heated suspensions and all were found to be negative (Table 2).

One hundred-and-six ETEC which did not possess any known colonization factors were also tested with the absorbed E7476A antiserum (Table 2). Three strains reacted with the antiserum, two $\mathrm{ST}^{+} \mathrm{LT}^{+}$strains of serotype $098: \mathrm{H}^{-}$and one $\mathrm{ST}^{+}$strain of serotype $\mathrm{O} 71: \mathrm{H} 27$. Like the strains of serogroup O166, they all gave MRHA with bovine and human red blood cells, contained a plasmid of 84 to $100 \mathrm{MDa}$ and produced two prominent polypeptides of 15.5 and $17.0 \mathrm{kDa}$ which reacted with the absorbed anti-strain E7476A antiserum in immunoblots.

Examination of E. coli strains carrying plasmid TP224::Tn10

When an E. coli K12 strain and E. coli strains of serotypes O6:H16, O40:H3, O71:H48, O128:H10, O128:H49, O154:H4 and O159:H34 containing plasmid TP224:Tn10 were streaked onto CFA agar containing bile salts and tested for MRHA of bovine red blood cells, all were positive although the reaction of the $E$. coli $\mathrm{K} 12$ strain was weak. When heated suspensions were tested in the ELISA with the absorbed anti-strain E7476 antiserum all were positive.

\section{DISCUSSION}

The ability of pathogenic $E$. coli of both human and animal origin to agglutinate red blood cells in the presence of mannose frequently correlates with the possession of colonization factors (Parry \& Rooke, 1985; De Graaf \& Mooi, 1986). When strains belonging to serogroup O166 were initially tested they did not cause MRHA of bovine, human or guinea-pig red blood cells (Gross et al., 1985). However, expression of MRHA is dependent on the medium on which a strain is cultured (Parry \& Rooke, 1985). Thomas (1985) observed that a strain of serotype O15:H11 only gave good MRHA if it was grown on MacConkey agar before incubation on CFA agar. When the strains of serogroup $\mathrm{O} 166$ were cultured in this way, the ST-positive strains all agglutinated bovine and human red blood cells in the presence of mannose. It was 
subsequently found that if one of the ingredients of MacConkey agar, bile salts, was added to the CFA agar the initial incubation step on MacConkey agar could be omitted.

The fimbriae produced by the type strain E7476 were rigid rod-shaped structures, similar to those of CFA/I, CS1, CS2, CS4, CFA/III and PCFO159:H4 but antigenically distinct. The inability of the variant E7476B to give MRHA was associated with the absence of fimbriae on the bacterial cells. Variant E7476B did not produce ST and had lost a $98 \mathrm{MDa}$ plasmid. When this $98 \mathrm{MDa}$ plasmid (TP224) marked with tetracycline resistance to give plasmid TP224:: Tn 10 was transferred to $E$. coli $\mathrm{K} 12$ or other serotypes of $E$. coli the transconjugants possessed MRHA ability and produced ST. Therefore plasmid TP224 coded for enterotoxin and fimbriae production like other plasmids which coded for known colonization factors and enterotoxins, e.g. CFA/I-ST, CFA/II-ST-LT, CS5-CS6-ST and PCFO159:H4-ST-LT (McConnell et al., 1981, 1988; Smith et al., 1983; Tacket et al., 1987).

The similarity of the properties of E7476 fimbriae to those of other colonization factors and the ability of fimbriate E7476 cells to adhere to human enterocytes (S. Knutton, personal communication) suggest that these fimbriae are also a colonization factor. The adhesin has provisionally been designated putative colonization factor O166 (PCFO166). It was also detected in other strains of serogroup O166, two strains of serotype $\mathrm{O} 98: \mathrm{H}^{-}$and one of serotype O71:H27. Although PCFO166 was found in only a few serogroups of $E$. coli in this survey, the fact that it was coded for by an autotransferring plasmid and could be expressed in E. coli of all the serogroups tested means that in time it may become more widely dispersed.

When fimbrial preparations of strain E7476 and other strains of the same serogroup were analysed by SDS-PAGE, two polypeptides of typical fimbrial subunit size were seen in MRHApositive but not in MRHA-negative strains. Although both polypeptides reacted with the absorbed antiserum prepared against strain E7476A, only one immunoprecipitate was seen on immunodiffusion, suggesting that the fimbriae may be composed of two subunits of different molecular mass rather than that two distinct types of fimbriae with a different subunit structure were present. However, we have previously found that immunodiffusion tests are not entirely reliable (McConnell et al., 1985) so that further work is necessary to establish the exact nature of the surface protein(s) and to examine more closely their role in adhesion.

This work was supported by a grant from the Diarrhoeal Diseases Control Programme of the World Health Organization.

\section{REFERENCES}

Anderson, E. S. \& Threlfall, E. J. (1974). The characterisation of plasmids in the enterobacteria. Journal of Hygiene 72, 471-487.

Birnboim, H. C. \& Doly, J. (1979). A rapid alkaline extraction procedure for screening recombinant plasmid DNA. Nucleic Acids Research 7, 15131523.

Changchawalit, S., Echeverria, P., Taylor, D. N., LeKsomboon, U., Tirapat, C., EAmpokalap, B. \& RowE, B. (1984). Colonization factors associated with enterotoxigenic Escherichia coli isolated in Thailand. Infection and Immunity 45, 525-527.

Cravioto, A., Scotland, S. M. \& Rowe, B. (1982). Hemagglutination activity and colonization factor antigens I and II in enterotoxigenic and non-enterotoxigenic strains of Escherichia coli isolated from humans. Infection and Immunity 36, 189-197.

Cravioto, A., Reyes, R. A., Ortega, R., Fernandez, G., Hernandez, R. \& LoPez, D. (1988). Prospective study of diarrhoeal disease in a cohort of rural Mexican children: incidence and isolated pathogens during the first two years of life. Epidemiology and Infection 101, 123-134.

Darfeuille-Michaud, A., Forestier, C., Joly, C. \& Cluzel, R. (1986). Identification of a nonfimbrial adhesive factor of an enterotoxigenic Escherichia coli strain. Infection and Immunity 52, 468-475.

Darfeuille-Michaud, A., Forestier, C., MasseBOEUf, R., Rich, C., M'Boup, S., Joly, B. \& Denis, F. (1987). Multiplicity of serogroups and adhesins in enteropathogenic and enterotoxigenic Escherichia coli isolated from acute diarrhea in Senegal. Journal of Clinical Microbiology 25, 1048-1051.

Dean, A. G., Ching, Y.-C., Williams, R. G. \& HARDEN, L. B. (1972). Test for Escherichia coli enterotoxin using infant mice. Application in a study of diarrhea in children in Honolulu. Journal of Infectious Diseases 125, 407-411.

De GraAF, F. K. \& Moor, F. R. (1986). The fimbrial adhesins of Escherichia coli. Advances in Microbial Physiology 28, 65-143.

Donta, S. T., Moon, H. W. \& Whipp, S. C. (1974). Detection of heat-labile Escherichia coli enterotoxin with the use of adrenal cells in tissue culture. Science 183, 334-336.

Evans, D. G. \& Evans, D. J., JR (1978). New surfaceassociated heat-labile colonization factor antigen (CFA/II) produced by enterotoxigenic Escherichia coli of serogroups $\mathrm{O} 6$ and $\mathrm{O} 8$. Infection and Immunity 21, 638-647. 
Evans, D. G., Silver, R. P., Evans, D. J., JR, Chase, D. G. \& Gorbach, S. L. (1975). Plasmid-controlled colonization factor associated with virulence in Escherichia coli enterotoxigenic for humans. Infection and Immunity 12, 656-667.

FrédérICQ, P. (1957). Colicins. Annual Review of Microbiology 11, 7-22.

Gross, R. J., Thomas, L. V. \& Rowe, B. (1985). Enterotoxigenic Escherichia coli strains belonging to a new serogroup, Escherichia coli O166. Journal of Clinical Microbiology 22, 705-707.

Honda, T., Khan, M. M. A., Takeda, Y. \& MiWATANI, T. (1983). Grouping of enterotoxigenic Escherichia coli by hydrophobicity and its relation to hemagglutination and enterotoxin production. FEMS Microbiology Letters 17, 273-276.

Honda, T., Arita, M. \& Miwatani, T. (1984). Characterization of new hydrophobic pili of human enterotoxigenic Escherichia coli: a possible new colonization factor. Infection and Immunity 43, 959965.

KnUtton, S., Lloyd, D. R. \& MCNeish, A. S. (1987). Identification of a new fimbrial structure in enterotoxigenic Escherichia coli (ETEC) serotype O148:H28 which adheres to human intestinal mucosa: a potentially new human ETEC colonization factor. Infection and Immunity 55, 86-92.

LAEMMLI, U. K. (1970). Cleavage of structural proteins during the assembly of the head of bacteriophage T4. Nature, London 227, 680-685.

LeVine, M. M., Ristaino, P., Sack, R. B., KAPer, J. B., ØRSKOV, F. \& ØRSKOV, I. (1983). Colonization factor antigens I and II and type 1 somatic pili in enterotoxigenic Escherichia coli: relation to enterotoxin type. Infection and Immunity 39, 889-897.

McConnell, M. M. \& Rowe, B. (1989). Prevalence of the putative colonization factors CFA/III and PCFO159:H4 in enterotoxigenic Escherichia coli. Journal of Infectious Diseases 159 (in the Press).

MCConnell, M. M., Smith, H. R., Willshaw, G. A., FIELD, A. M. \& Rowe, B. (1981). Plasmids coding for colonization factor antigen 1 and heat-stable enterotoxin production isolated from enterotoxigenic Escherichia coli: comparison of their properties. Infection and Immunity 32, 927-936.

McConnell, M. M., Thomas, L. V., Day, N. P. \& Rowe, B. (1985). Enzyme-linked immunosorbent assays for the detection of adhesion factor antigens of enterotoxigenic Escherichia coli. Journal of Infectious Diseases 152, 1120-1127.

McConnell, M. M., Thomas, L. V., Scotland, S. M. \& Rowe, B. (1986). The possession of coli surface antigen CS6 by enterotoxigenic Escherichia coli of serogroups $\mathrm{O} 25, \mathrm{O} 27, \mathrm{O} 148$ and O159: a possible colonization factor. Current Microbiology 14, 51-54.

McConnell, M. M., Thomas, L. V., Willshaw, G. A., Smith, H. R. \& Rowe, B. (1988). Genetic control and properties of coli surface antigens of colonization factor antigen IV (PCF8775) of enterotoxigenic Escherichia coli. Infection and Immunity 56, 1974-1980.

Manning, P. A., Higgins, G. D., Lumb, R. \& LANSER, J. A. (1987). Colonization factor antigens and a new fimbrial type, CFA/V, on $\mathrm{O} 115: \mathrm{H} 40$ and $\mathrm{H}^{-}$strains of enterotoxigenic Escherichia coli in Central Australia. Journal of Infectious Diseases 156, 841-844.
Merson, M. H., Black, R. E., Khan, M. U. \& HuQ, I. (1980). Epidemiology of cholera and enterotoxigenic Escherichia coli diarrhoea. In Cholera and Related Diseases, 43rd Nobel Symposium, Stockholm, pp. 34-45. Edited by O. Ouchterlony \& J. Holmgren. Basel: S. Karger.

ParRy, S. H. \& Rooke, D. M. (1985). Adhesins and colonization factors of Escherichia coli. In The Virulence of Escherichia coli, Society for General Microbiology Special Publication no. 13, pp. 79-156. Edited by M. Sussman. London: Academic Press.

SACK, R. B. (1975). Human diarrheal disease caused by enterotoxigenic Escherichia coli. Annual Review of Microbiology 29, 333-353.

Scotland, S. M., Gross, R. J., Cheasty, T. \& Rowe, B. (1979). The occurrence of plasmids carrying genes for both enterotoxin production and drug resistance in Escherichia coli of human origin. Journal of Hygiene 83, 531-538.

Scotland, S. M., Day, N. P. \& Rowe, B. (1983). Acquisition and maintenance of enterotoxin plasmids in wild-type strains of Escherichia coli. Journal of General Microbiology 129, 3111-3120.

Scotland, S. M., McConnell, M. M., Willshaw, G. A., Rowe, B. \& Field, A. M. (1985). Properties of wild-type strains of enterotoxigenic Escherichia coli which produce colonization factor antigen II, and belong to serogroups other than O6. Journal of General Microbiology 131, 2327-2333.

Smith, H. R., Scotland, S. M. \& Rowe, B. (1983). Plasmids that code for production of colonization factor antigen II and enterotoxin production in strains of Escherichia coli. Infection and Immunity 40 , 1236-1239.

SMYTH, C. J. (1982). Two mannose-resistant haemagglutinins on enterotoxigenic Escherichia coli of serotype $06: \mathrm{K} 15: \mathrm{H} 16$ or $\mathrm{H}^{-}$isolated from travellers' and infantile diarrhoea. Journal of General Microbiology 128, 2081-2096.

Stevenson, P. \& Griffiths, E. (1985). Detection of antibodies and antigens by immunoblotting. In The Virulence of Escherichia coli, Society for General Microbiology Special Publication no. 13, pp. 457464. Edited by M. Sussman. London: Academic Press.

TaCket, C. O., Maneval, D. R. \& Levine, M. M. (1987). Purification, morphology and genetics of a new fimbrial putative colonization factor of enterotoxigenic Escherichia coli $\mathrm{O} 159: \mathrm{H} 4$. Infection and Immunity 55, 1063-1069.

Thomas, L. V. (1985). An investigation of the adhesive properties of enterotoxigenic Escherichia coli isolated from humans. $\mathrm{PhD}$ thesis, CNAA.

Thomas, L. V. \& RowE, B. (1982). The occurrence of colonisation factors (CFA/I, CFA/II and E8775) in enterotoxigenic Escherichia coli from various countries in South East Asia. Medical Microbiology and Immunology 171, 85-90.

Thomas, L. V., McConnell, M. M., Rowe, B. \& FIELD, A. M. (1985). The possession of three novel coli surface antigens by enterotoxigenic Escherichia coli strains positive for the putative colonisation factor PCF8775. Journal of General Microbiology 131, 2319-2326.

Thomas, L. V., Rowe, B. \& McConnell, M. M. (1987). In strains of Escherichia coli 0167 a single 
plasmid encodes for the coli surface antigens CS5 and CS6 of putative colonization factor PCF8775, heat-stable enterotoxin and colicin Ia. Infection and Immunity 55, 1929-1931.

WEEKE, B. (1973). General remarks on principles, equipment, reagents and procedures. In $A$ Manual for Quantitative Immunoelectrophoresis. Edited by N.
Axelsen, H. Kroel \& B. Weeke. Scandinavian Journal of Immunology 2, (suppl. 1), 15-35.

Willshaw, G. A., Smith, H. R. \& Anderson, E. S. (1979). Application of agarose gel electrophoresis to the characterisation of plasmid DNA in drugresistant enterobacteria. Journal of General Microbiology 114, 15-25. 